\title{
Acute exposure of mice to high-dose ultrafine carbon black decreases susceptibility to pneumococcal pneumonia
}

\author{
Ananth Tellabati ${ }^{1}$, Vitor E Fernandes ${ }^{2}$, Friederike Teichert ${ }^{2}$, Rajinder Singh ${ }^{2}$, Jamie Rylance ${ }^{3}$, Stephen Gordon ${ }^{3}$, \\ Peter W Andrew ${ }^{1}$, Jonathan Grigg ${ }^{4^{*}}$
}

\begin{abstract}
Background: Epidemiological studies suggest that inhalation of carbonaceous particulate matter from biomass combustion increases susceptibility to bacterial pneumonia. In vitro studies report that phagocytosis of carbon black by alveolar macrophages (AM) impairs killing of Streptococcus pneumoniae. We have previously reported high levels of black carbon in AM from biomass smoke-exposed children and adults. We therefore aimed to use a mouse model to test the hypothesis that high levels of carbon loading of AM in vivo increases susceptibility to pneumococcal pneumonia.

Methods: Female outbred mice were treated with either intranasal phosphate buffered saline (PBS) or ultrafine carbon black (UF-CB in PBS; $500 \mu \mathrm{g}$ on day 1 and day 4), and then infected with S. pneumoniae strain D39 on day 5. Survival was assessed over $72 \mathrm{~h}$. The effect of UF-CB on AM carbon loading, airway inflammation, and a urinary marker of pulmonary oxidative stress was assessed in uninfected animals.

Results: Instillation of UF-CB in mice resulted a pattern of AM carbon loading similar to that of biomass-smoke exposed humans. In uninfected animals, UF-CB treated animals had increased urinary 8-oxodG $(P=0.055)$, and an increased airway neutrophil differential count $(P<0.01)$. All PBS-treated mice died within $72 \mathrm{~h}$ after infection with S. pneumoniae, whereas morbidity and mortality after infection was reduced in UF-CB treated animals (median survival 48 h vs. 30 h, P < 0.001). At 24 hr post-infection, UF-CB treated mice had lower lung and the blood S. pneumoniae colony forming unit counts, and lower airway levels of keratinocyte-derived chemokine/growth-related oncogene (KC/GRO), and interferon gamma.
\end{abstract}

Conclusion: Acute high level loading of AM with ultrafine carbon black particles per se does not increase the susceptibility of mice to pneumococcal infection in vivo.

\section{Background}

Streptococcus pneumoniae is responsible for a significant proportion of global pneumonia deaths [1]. Growing antibiotic resistance, and lack of availability of antibiotics and vaccines, has focussed attention on the preventable environmental risk factors for bacterial pneumonia. In low-income countries, the burning of biomass fuels results in concentrations of inhalable carbonaceous

\footnotetext{
* Correspondence: j.grigg@qmul.ac.uk

${ }^{4}$ Centre for Paediatrics, Blizard Institute of Cell and Molecular Science, Barts and the London School of Medicine and Dentistry, Queen Mary University London, London, E1 2AT, UK

Full list of author information is available at the end of the article
}

particulate matter (PM) exceeding $8000 \mu \mathrm{g} / \mathrm{m}^{3}$, [2] with young children and women differentially exposed [3],

Epidemiological studies strongly suggest that indoor PM from biomass and solid fuel combustion is one of the most significant environmental risk factors for bacterial pneumonia in low-income countries [4]. However to date, little is known about how carbonaceous PM increases susceptibility to pneumococcal infection. An important component of pulmonary defences against pneumococcal pneumonia is the alveolar macrophage (AM) [5]). Studies of AM in vitro suggest that phagocytosis of PM impairs the ability of AM to subsequently kill bacteria. First, Lundborg et al [6] reported a 
dose-dependent increase in the survival of $S$ pneumoniae in rat AM loaded with ultrafine carbon black in vitro. Second, Zhou and Kobzik [7] reported in a mouse model, that AM phagocytosis of carbonaceous urban PM in vitro impairs their ability to subsequently internalise S. pneumoniae.

We have previously reported high levels of carbon in AM associated from biomass-smoke exposed children and women living in Ethiopia [8], and from adults living in Malawi [9]. Since elemental carbon nanoparticles are a major, and potentially toxic, component of biomass smoke PM [10], we hypothesised that susceptibility to pneumococcal pneumonia is increased by carbon loading of AM in vitro. Using a mouse model, we sought to test this hypothesis by loading AM with ultrafine carbon black (UF-CB) in vivo (2x doses of $500 \mu \mathrm{g}$ UF-CB), and then assessing morbidity and mortality to subsequent intranasal pneumococcal infection.

\section{Results}

\section{Ultrafine carbon black loading}

The effect of UF-CB alone was assessed in uninfected animals by bronchoalveolar lavage (BAL) and lung histology. No short- or long-term morbidity was observed in animals exposed to UF-CB alone. Bronchoalveolar lavage of PBS-alone treated animals showed no evidence of AM carbon $(\mathrm{n}=10)$. In UF-CB alone treated animals $(\mathrm{n}=10), 44 \pm 1.1 \%$ of AM were heavily-laden with carbon and $17.6 \pm 1.1$ moderately-laden (Figure 1). The pattern of carbon in mouse AM after instillation of UFCB was similar to that seen in AM from biomass-smoke exposed humans (Figure 2) $[8,9]$.

Lung histology confirmed no inflammation and no AM carbon in mice exposed to PBS alone (Table 1, Fig 3A). After UF-CB alone, most carbon was in AM (Table 1, Fig 3B,C), although minimal uptake of carbon by bronchiolar epithelial cells was also observed (Table 1). In UF-CB alone treated animals, there was a mild inflammatory response characterised by infiltration of leukocytes, predominantly neutrophils (Table 1). Compatible with histological findings, analysis of BAL fluid at $72 \mathrm{~h}$ post instillation showed an increased proportion of neutrophils in UF-CB alone treated animals $(\mathrm{n}=10,0.06 \pm$ $0.04 \%$ vs. $2.0 \pm 0.42 \%, P<0.01$, Fig 4 ). UF-CB alone treated animals had increased urinary 8-oxodG $(12.1 \pm 0.8$ vs. $14.5 \pm 0.6 \mathrm{pmol} / \mathrm{mL}, P=0.055$, vs. $\mathrm{PBS}$ ) suggestive of increased pulmonary oxidative stress (Fig 5).

\section{Survival}

Survival after infection with S. pneumoniae was assessed up to $72 \mathrm{~h}$. Initial experiments included uninfected (PBS alone and UF-CB alone) animals. However, no morbidly or mortality was observed in these uninfected animals. Additional survival experiments therefore used infected mice only (Figure 6). All PBS-treated animals succumbed from pneumococcal infection by $72 \mathrm{~h}$. In contrast, exposure to UF-CB consistently delayed time to death from infection and increased morbidity-free survival at $72 \mathrm{~h}$ (Figure $6, P<0.001, \log$ rank test). Survival of UF-CB treated animals from pneumococcal infection at $72 \mathrm{~h}$ in over 4 separate experiments was between $40 \%$ and $60 \%$, with surviving animals remaining disease-free for several days after the experiment.

\section{Tissue infection}

To determine whether increased survival after exposure to UF-CB was associated with decreased bacterial load in lung tissue, pneumococcal CFU counts were measured up to $24 \mathrm{~h}$. Lung CFU counts were initially low in both PBS- and UF-CB-treated groups at 4 and $6 \mathrm{~h}$ after infection $(P=\mathrm{NS}$, Figure 7$)$. However by $12 \mathrm{~h}$, lung CFU counts were lower in UF-CB treated animals, and by $24 \mathrm{~h}$ this decrease was significant (Figure $7, P<0.01$, $\mathrm{n}=5$ ). In a separate $24 \mathrm{~h}$ experiment, mice treated with UF-CB had significantly lower blood CFU counts (Figure $8, \mathrm{n}=6, \mathrm{P}<0.05$ vs. PBS control). Exploratory analysis of BAL fluid cytokines was done in both uninfected and infected animals at $24 \mathrm{~h}$. Treatment with UF-CB alone did not increase BAL fluid keratinocyte-derived chemokine/growth-related oncogene (KC/GRO), TNF- $\alpha$ or IF- $\gamma$ (Figure 9, $\mathrm{n}=5$ ). Pneumococcal infection increased BAL cytokines at $24 \mathrm{~h}(P<0.05$ vs. uninfected $)$. However, BAL fluid cytokines in infected mice treated with UF-CB tended be lower (Figure 9, KC/GRO; $\mathrm{P}=0.06$, TNF- $\alpha ; \mathrm{P}=\mathrm{NS}$, and IF- $\gamma ; \mathrm{P}<0.05)$.

\section{Discussion}

This study was designed to assess the hypothesis that loading of AM with particles of ultrafine elemental carbon increases susceptibility to pneumococcal pneumonia. In conflict with the hypothesis, using an established animal model of pneumococcal pneumonia, we found that mice exposed to UF-CB were partially protected against the consequences of pneumococcal infection, with delayed morbidity and reduced mortality at $72 \mathrm{~h}$ and no evidence of late-onset infection in the surviving animals.

This is the first report of a protective effect of carbonaceous PM on bacterial pneumonia. To date, increased susceptibility to bacterial infection has been reported after exposure to environmental PM. For example in rats, inhalation of aerosolised diesel exhaust particles $(20 \mathrm{mg} /$ $\mathrm{m}^{3}$ for $4 \mathrm{~h}$ a day for 5 days) followed by Listeria infection, increased Listeria lung CFU counts [11]. In another example, a dose-dependent increase in S. Aureus CFU counts occurred in rabbits after inhalation of wood smoke for $1 \mathrm{~h}$ per day for 4 days [12]. One previous study has addressed the interaction between carbonaceous PM 


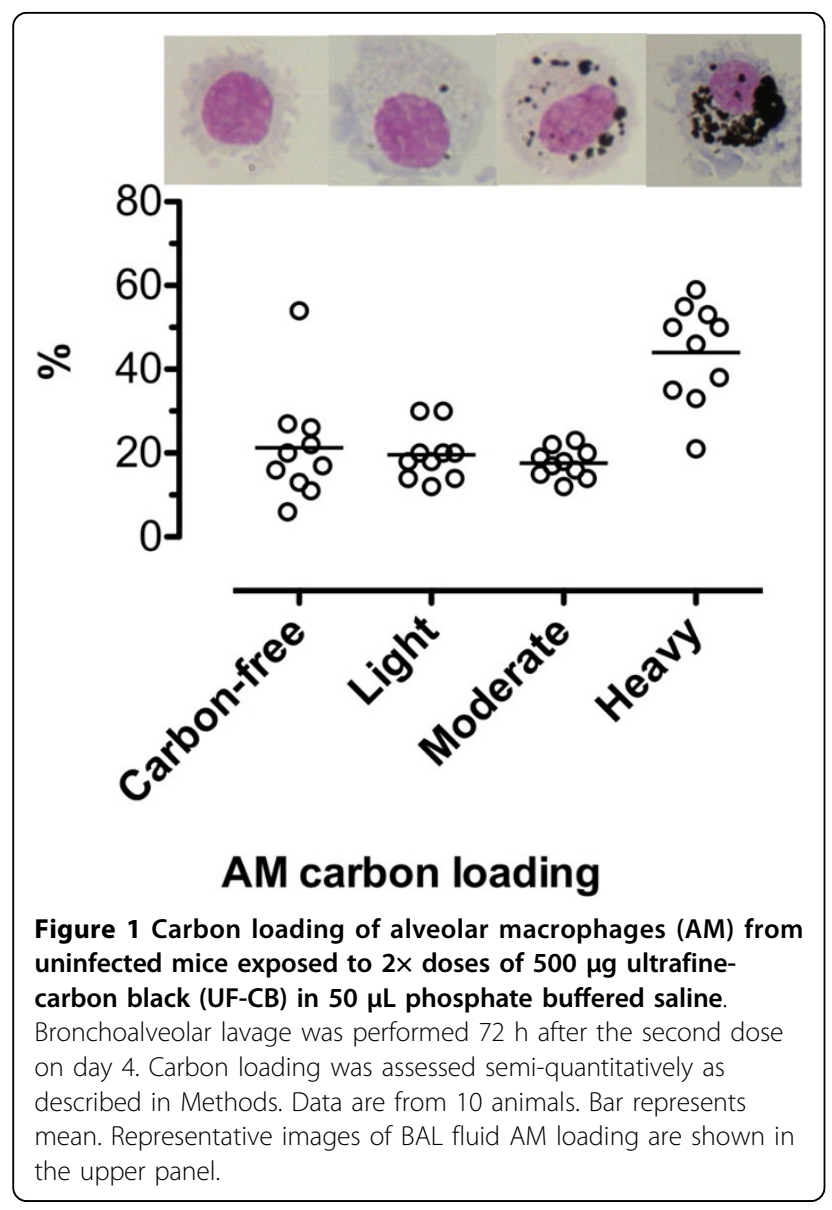

and susceptibility to pneumococcal pneumonia. Sigaud et al [13] exposed BALB/c mice to aerosolised interferon gamma, then instilled concentrated ambient particles intra-nasally, followed by infection with S. pneumoniae. In this model, all untreated mice survived and cleared instilled bacteria by $24 \mathrm{~h}$. By contrast, mice exposed to concentrated ambient particles and interferon gamma, had increased BAL neutrophils and more severe pneumonia at $24 \mathrm{~h}$. However, there are significant differences

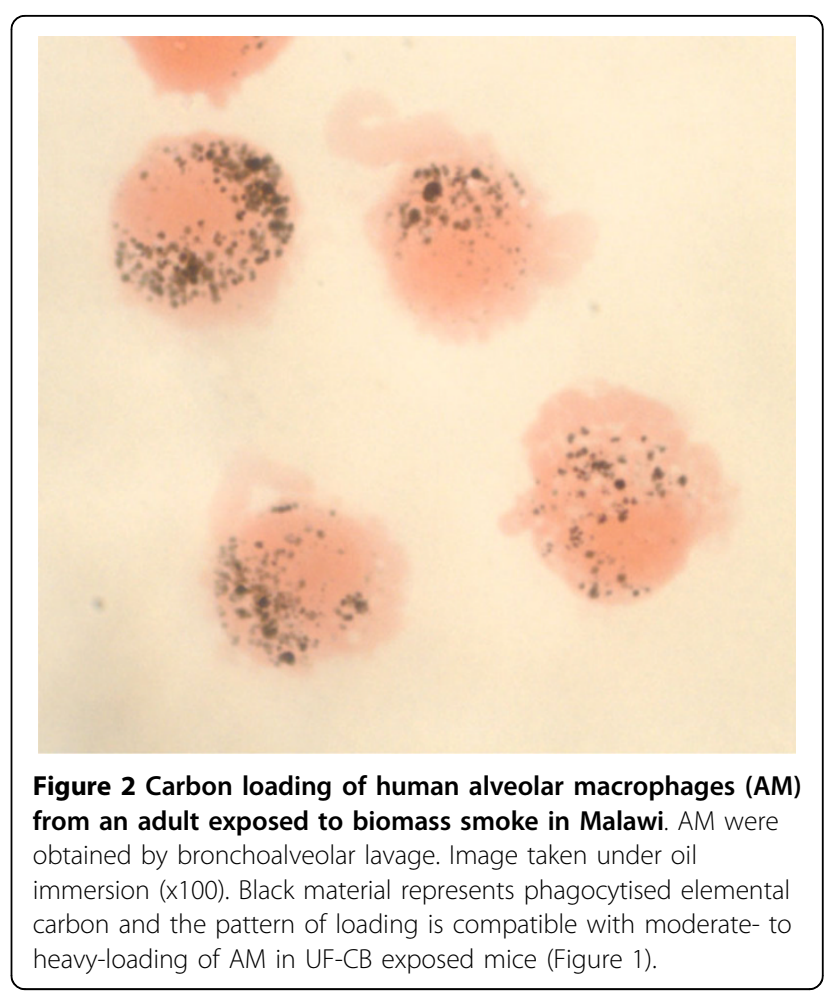

between our model and that of Sigaud et al [13], i.e. we used UF-CB as a surrogate for the carbonaceous fraction of biomass PM, and all untreated mice died from pneumococcal disease by $72 \mathrm{~h}$.

Lung tissue injury, by damaging airway epithelial integrity would be expected to enhance susceptibility to bacterial infection. Indeed, we found changes in lung histology after UF-CB installation suggestive of mild tissue injury. However, UF-CB treatment resulted in consistently lower levels of pulmonary pneumococcal CFU counts after infection, and attenuated the induction of $\mathrm{KC} / \mathrm{GRO}$, and IF- $\gamma$. Since there was no difference in lung CFU counts immediately after instillation of bacteria (data not shown) and at $4 \mathrm{~h}$ and $6 \mathrm{~h}$ after infection

Table 1 Lung histology in uninfected mouse lung tissue $72 \mathrm{~h}$ after intranasal instillation in vivo of either phosphate buffered saline (PBS) or ultrafine carbon black $(2 \times 500 \mu \mathrm{g})$

\begin{tabular}{|c|c|c|c|}
\hline \multicolumn{2}{|r|}{ Alveolar } & \multicolumn{2}{|r|}{ Bronchiolar } \\
\hline PBS & Ultrafine-Carbon black & PBS & Ultrafine Carbon Black \\
\hline $\begin{array}{l}\text { Minimal diffuse alveolar } \\
\text { microvascular congestion }\end{array}$ & $\begin{array}{l}\text { Moderate to marked black particle inclusions - mainly within } \\
\text { alveolar macrophages associated with moderate to marked } \\
\text { secondary pneumonic reaction }\end{array}$ & Normal & $\begin{array}{l}\text { Moderate sporadic black particle inclusions } \\
\text { within bronchiolar epithelium }\end{array}$ \\
\hline \multirow[t]{3}{*}{$\begin{array}{l}\text { Minimal sporadic alveolar } \\
\text { macrophage and } \\
\text { neutrophil foci }\end{array}$} & Marked diffuse alveolar microvascular congestion & & $\begin{array}{l}\text { Marked multi-focal leucocyte infiltration of } \\
\text { airway walls - mainly neutrophils and } \\
\text { mononuclear cells }\end{array}$ \\
\hline & $\begin{array}{l}\text { Marked diffuse pneumonitis with consolidated microvascular } \\
\text { leak }\end{array}$ & & $\begin{array}{l}\text { Moderate multi-focal hypertrophy of } \\
\text { transitional airway epithelium }\end{array}$ \\
\hline & & & $\begin{array}{l}\text { Moderate to marked focal hypertrophy of } \\
\text { mesothelium }\end{array}$ \\
\hline
\end{tabular}




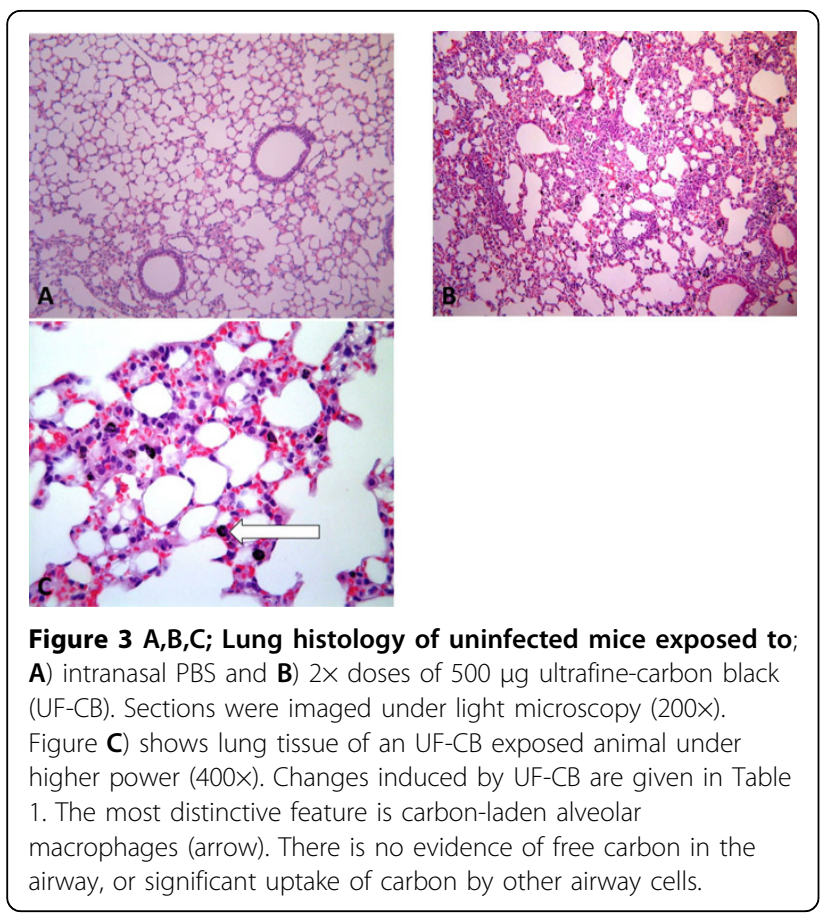

in UF-CB and PBS-treated groups, the possibility that UF-CB treated mice had lower number of instilled bacteria is excluded. Compatible with the reduced lung CFU counts up to $24 \mathrm{~h}$ in UF-CB exposed mice, and lower pro-inflammatory cytokine levels, and fewer

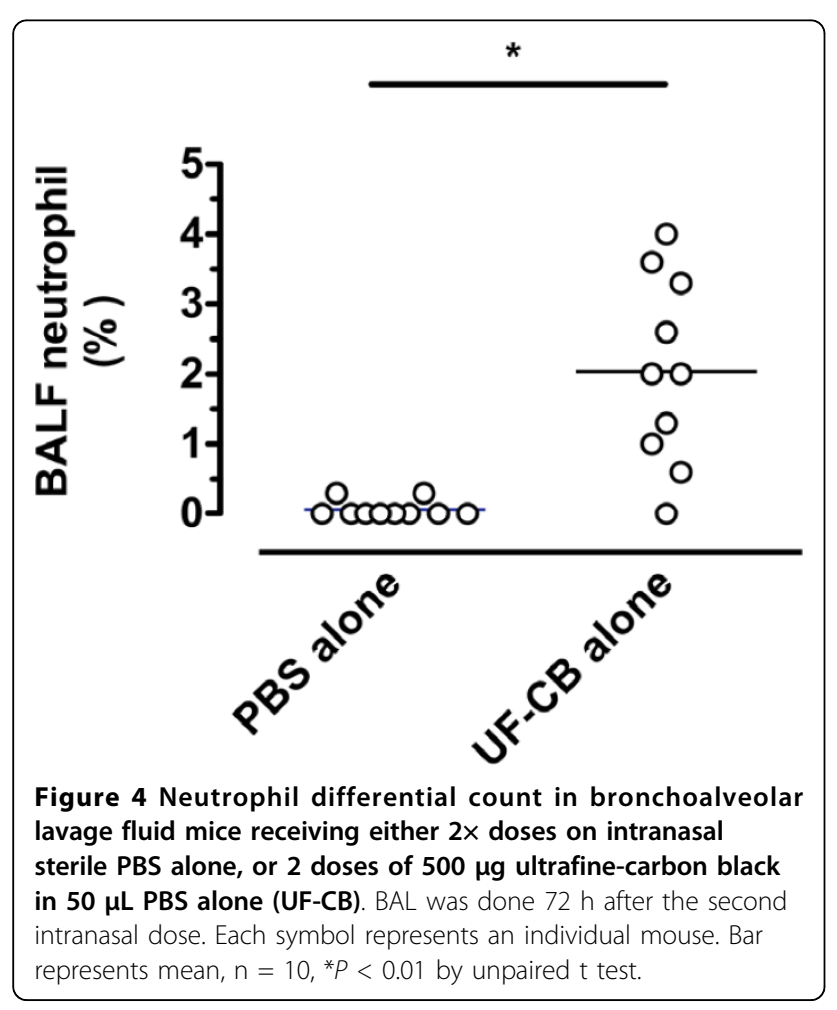

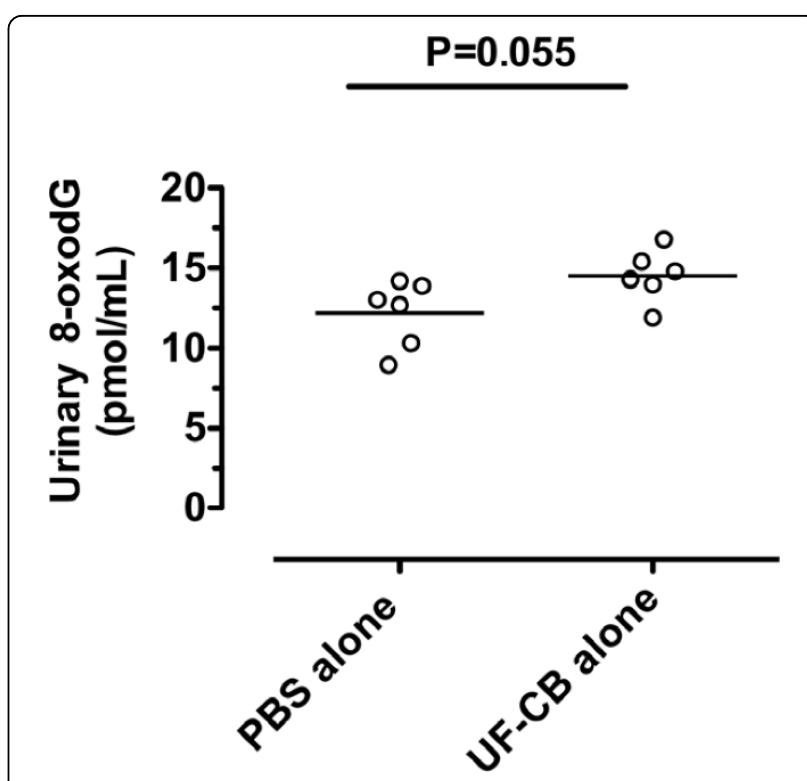

Figure 5 Urinary 8-oxodG in the urine of mice treated with i) $2 \times$ intranasal doses of PBS alone, and ii) $2 \times$ intranasal doses of $500 \mu \mathrm{g}$ ultrafine-carbon black (UF-CB) in PBS alone. Urine was collected $72 \mathrm{~h}$ after the second intranasal instillation. 8-oxodG was assayed by liquid chromatography-electrospray ionization-tandem mass spectrometry and results corrected for specific gravity. Bar represents mean, $\mathrm{n}=6$ per group, ${ }^{*} P=0.055$ by unpaired t test.

carbon-exposed animals developed pneumococcal bacteraemia at $24 \mathrm{~h}$.

The mechanism whereby an acute does of UF-CB protects mice against pneumococcal morbidity and mortality is unclear. Increased anti-pneumococcal function in

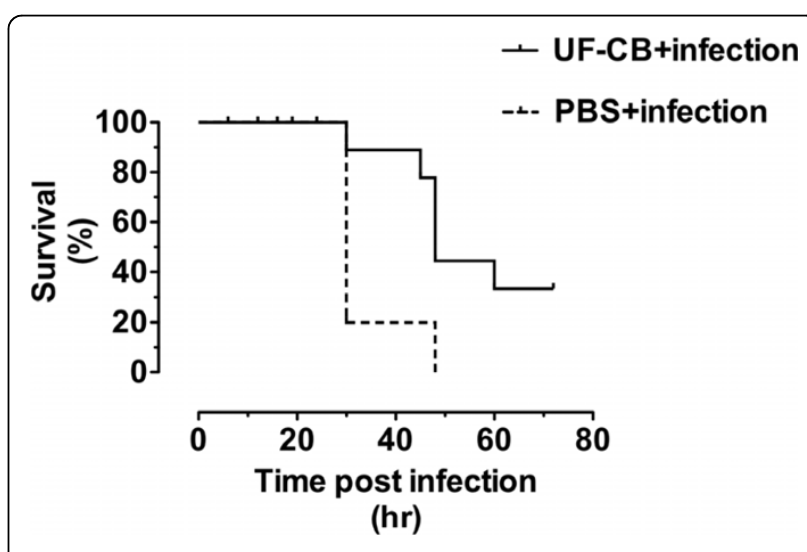

Figure 6 Survival curves of mice infected with pneumococci and pre-treated with; i) $2 \times$ intranasal doses of sterile PBS (PBS +infection) and ii) $2 \times$ intranasal doses of $500 \mu \mathrm{g}$ ultrafinecarbon black (UF-CB + infection). Animals treated with PBS alone or UF-CB alone had no morbidity (data not shown). Data shown are representative of $>4$ separate experiments done at different times each with 10 animals per group. In the data plotted, median survival of PBS treated mice was $30 \mathrm{~h}$. In contrast, median survival in UF-CB treated mice was $48 \mathrm{~h}$ (hazard ratio 8.5 ( $95 \% \mathrm{Cl} 2.0$ to 36 ), $P<0.001$ by log rank test). 


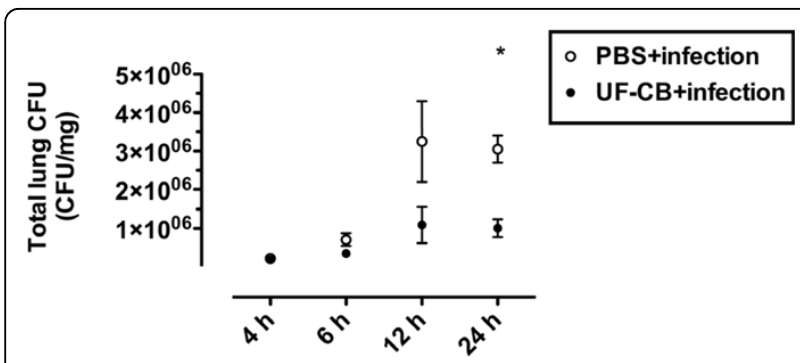

Figure 7 Total lung tissue colony forming unit (CFU) counts in infected mice pre-treated with; i) $2 \times$ intranasal doses of sterile PBS, and ii) $2 \times$ intranasal doses of $\mathbf{5 0 0} \mu \mathrm{g}$ ultrafine-carbon black (UF-CB). At $24 \mathrm{~h}$ post-instillation of $S$ pneumonaie, there is a significant decrease in UF-CB treated animals. Data are described by mean \pm SEM, $n=5$ for each time point for each group. ${ }^{*} P<0.01$ by unpaired $t$ test.

carbon-laden AM is unlikely, since loading of AM with UF-CB in vitro significantly impairs pneumococcal killing [6]. In the rat, instillation of endotoxin results in recruitment of neutrophils into the lung and protection against subsequent death from Pseudomonas aeruginosa

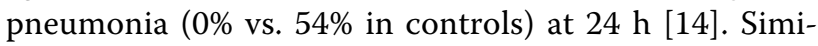
larly, we found in both BAL and lung tissue, that UF$\mathrm{CB}$ induces a mild pulmonary neutrophilia. Endotoxin contamination of UF-CB is not a stimulus for the pulmonary neutrophilia observed in the present study, since particles were baked at high temperature for several hours before use. Previous animal studies have shown UF-CB alone, via oxidative stress, induce a low grade airway neutrophilia [15]. Increased urinary

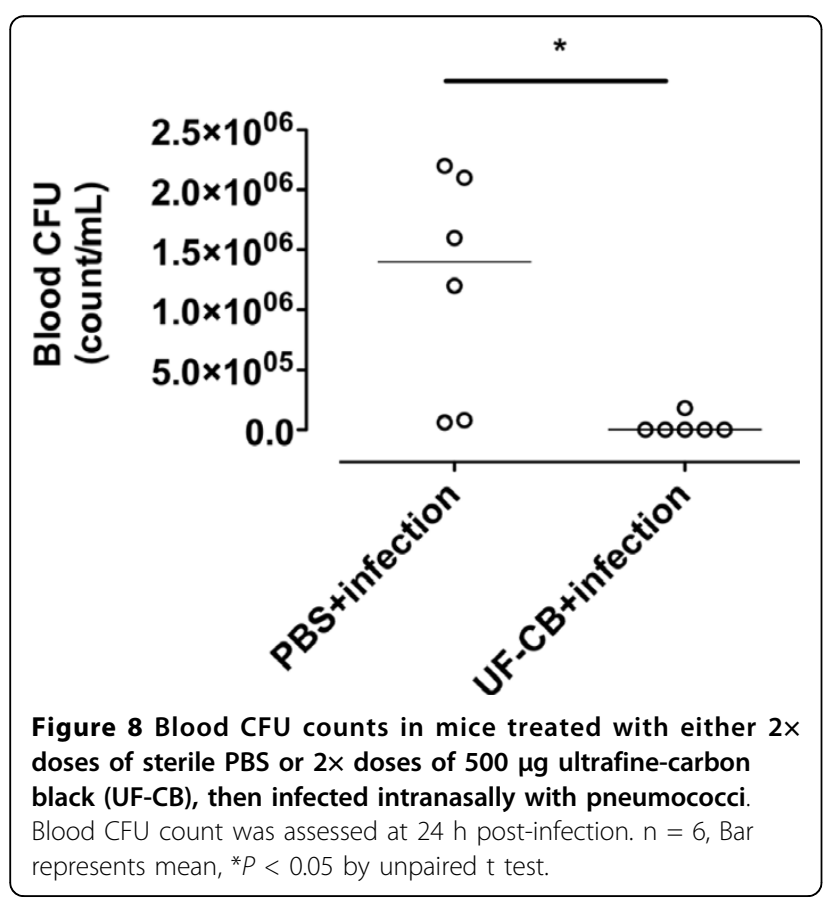

8-oxodG in UF-CB-exposed mice in the present study is suggestive of increased pulmonary oxidative stress $[16,17]$. We therefore speculate that partial protection against pneumonia in UF-CB exposed mice is due to oxidative stress stimulating the recruitment of neutrophils into the airway.

There are several limitations to our data. First, human AM acquire inhaled carbon over several months. To achieve a comparable degree of AM carbon loading, requires a high acute dose of ultrafine carbon black $(2 \times 500 \mu \mathrm{g}$ per animal). The effect of chronic loading of murine AM with repeated low doses of UF$\mathrm{CB}$ in vivo on vulnerability to pneumococcal pneumonia remains to be determined. Second, we have used lethal dose of pneumococci which does not model the effect of inhaled carbon on pneumococcal colonisation of the upper airway. However, pneumococcal pneumonia is a leading cause of death in young children - and our results therefore model vulnerability to death in children with established infection. Third, biomass PM consists not only of carbon nanoparticle aggregates (modeled in this study), but also adsorbed compounds such as metals (which we have not modeled). The potential importance of adsorbed compounds is suggested by Zhou and Kobzik [7], who reported decreased internalisation of S. pneumoniae and killing by a murine macrophage cell line loaded with concentrated ambient particles in vitro, but no impairment of internalisation when cells were loaded with carbon black. Indeed, we have previously shown that adsorbed metals in dungsmoke $\mathrm{PM}_{10}$ contribute to the induction of oxidative stress in a cell-free system [18]. Future animal studies of susceptibility to infection should therefore focus on unprocessed biomass PM.

\section{Conclusion}

We found no evidence to support our hypothesis that the epidemiological association between exposure to biomass smoke PM and susceptibility to pneumonia is due to high levels of carbon loading of AM per se. In female MF1 mice, pre-treatment with UF-CB results in lower lung and blood pneumococcal burden, and reduced morbidity and mortality. The mechanism for the protective effect is unknown, but may be due recruitment of low numbers of activated neutrophils into the lung prior to infection.

\section{Methods}

\section{Animals and ultrafine carbon black}

Female outbred MF1 mice (Harlan Olac, United Kingdom) aged $9 \mathrm{wk}$, were used for all the experiments. Animals were specific pathogen-free and provided with water and food pellets ad libitum. Ultrafine carbon black (UF-CB) (Printex 90, $14 \mathrm{~nm}$ diameter spherules, 


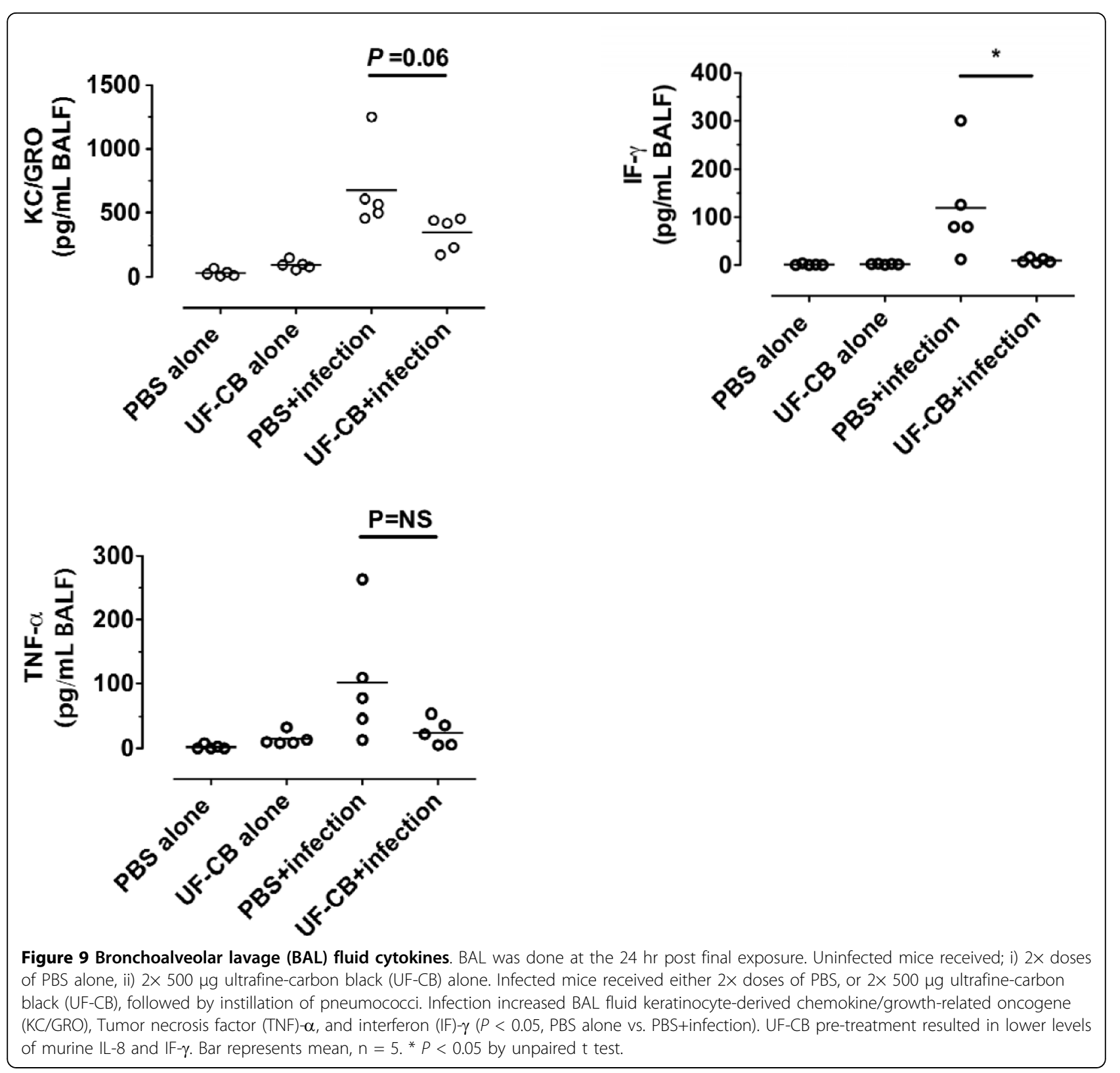

Degussa, Frankfurt, Germany) was a kind gift from Professor Ken Donaldson. UF-CB was baked at $240^{\circ} \mathrm{C}$. for $12 \mathrm{~h}$ before use. Prior to instillation, UF-CB was added to sterile PBS to produce a $10 \mu \mathrm{g} / \mu \mathrm{L}$ suspension. The suspension was sonicated $5 \times$ for $30 \mathrm{~s}$ prior to use.

\section{Streptococcus pneumoniae}

S. pneumoniae serotype 2 strain D39 was obtained from the National Collection of Type Cultures, London, UK. Pneumococci were cultured in Brian Heart Infusion (BHI) broth containing 20\% (v/v) fetal calf serum or on blood agar base containing $5 \% \mathrm{v} / \mathrm{v}$ horse blood. Bacteria were confirmed as pneumococci with an optochin disk (Oxoid, Basingstoke, UK) and Gram staining. Before use in intranasal infections, pneumococci were passaged through the mouse peritoneum and collected from cardiac blood as described previously [17]. Briefly, the inoculum was injected intra-peritoneally into mice and the cardiac blood was collected form terminally anesthetised animals at $24 \mathrm{~h}$. Pneumococci were harvested the next day by centrifugation, and resuspended in BHI containing 20\% (v/v) fetal calf serum for $4 \mathrm{~h}$ at $37^{\circ} \mathrm{C}$ to an $\mathrm{OD}_{500}$ of 1.6 . Bacterial viability count was assessed by counting colony forming units (CFU) on blood agar base plates with $5 \%(\mathrm{v} / \mathrm{v})$ horse blood (Oxoid, Basingstoke, UK). Aliquots of bacteria were then stored at $-80^{\circ} \mathrm{C}$. for mice infection experiments. 


\section{Infection protocol}

To assess the effect of exposure to UF-CB on susceptibility to pneumococcal infection, animals first received either intranasal sterile PBS or intranasal UF-CB (500 $\mu \mathrm{g}$ UF-CB in $50 \mu \mathrm{L}$ sterile PBS) on day 1 . To instil fluid into the lower airway, animals were lightly anesthetized with $2.5 \%(\mathrm{v} / \mathrm{v})$ fluothane (AstraZeneca, Macclesfield, $\mathrm{UK}$ ) over oxygen (1.5 to $2 \mathrm{~L} / \mathrm{min}$ ), held by the back of the neck, and sterile PBS or UF-CB suspended in PBS dropped onto the nose. On day 4, intranasal instillation of either PBS or UF-CB was repeated (i.e. total of 1000 $\mu \mathrm{g})$. On day 5 , animals received either intranasal $50 \mu \mathrm{L}$ sterile PBS or $1 \times 10^{6}$ colony forming units (CFU) $S$. pneumoniae in $50 \mu \mathrm{L}$ sterile PBS [19]. Mice were regularly monitored for signs of disease for up to $72 \mathrm{~h}$ after infection, or until they became severely lethargic, at which point animals were humanely sacrificed. To assess tissue CFU, lungs were homogenized in $5 \mathrm{~mL}$ sterile PBS with a tissue homogenizer (Jencons, Leighton Buzzard, UK). Serial dilutions were performed up to $10^{6}$ in using PBS as diluent. Dilutions of homogenates $(20 \mu \mathrm{L})$ were placed onto blood agar and the number of CFU counted after overnight incubation at $37^{\circ} \mathrm{C}$. Blood was also collected immediately post-mortem.

\section{Bronchoalveolar lavage of mice}

Bronchoalveolar lavage was obtained from mice by instilling $4 \times 500 \mu \mathrm{L}$ sterile PBS through a 25 -gauge needle into the lungs, via the trachea, followed by aspiration of BAL fluid into the syringe. BAL fluid was pooled form each animal and samples were kept on ice. BAL lavage fluid was cytocentrifuged (Shandon Instruments; Pittsburgh, PA), and cells stained with Diff-Quik (Dade Behring; Deerfield, IL, USA). The BAL fluid neutrophil differential count was obtained from randomly selected fields (light microscopy, oil immersion, $\times 100$ ) from 300 leukocytes. Carbon loading of AM was determined in 300 randomly selected AM using a semi-quantitative scale. Lightly-laden AM had less than $10 \%$ cytoplasmic particle burden, moderately-laden cells had 10 to $50 \%$ of the cytoplasm occupied by particles, and heavily-laden cells had more than $50 \%$ of their cytoplasm containing carbon black.

\section{Bronchoalveolar lavage of humans}

Sampling and BAL fluid processing of humans were done as previously described a biomass-smoke exposed population living in Blantyre, Malawi as a part of a previously published study into the association between solid fuel use and AM carbon-loading [8]. Sampling received ethical approval from the Research Ethics Committee of the Liverpool School of Tropical Medicine and the College of Medicine, University of Malawi.

\section{Bronchoalveolar lavage fluid cytokines}

Exploratory analysis of BAL fluid cytokines was done using a 96-well multi-spot plate for mouse cytokines obtained from Meso Scale Discovery (MSD, Gaithersburg, USA). The assay was performed according to the manufacturer's instructions. The time of incubation for standard and samples was $1.5 \mathrm{~h}$. The plate was read using a MSD SECTOR imager and data analyses was done using the discovery workbench software. Keratinocyte-derived chemokine/growth-related oncogene ( $\mathrm{KC} /$ GRO) - the murine ortholog of human interleukin-8, tumor necrosis factor alpha (TNF- $\alpha$ ) and interferon gamma (IF- $\gamma$ ) were defined a priori as the cytokines of interest.

\section{Urinary 8-oxodG assay}

To collect urine, mice were placed in metabolism cages. Urine was pooled and frozen at $-80^{\circ} \mathrm{C}$. prior to analysis. For analysis of 8-oxo-deoxyGuanosine (8-oxodG), a 100 $\mu \mathrm{L}$ aliquot of mouse urine sample was diluted with 890 $\mu \mathrm{L}$ of HPLC grade water and spiked with $10 \mathrm{pmol}$ of the stable isotope internal standard $\left[{ }^{15} \mathrm{~N}_{5}\right] 8$-oxodG $(1 \mathrm{pmol} / \mu \mathrm{L})$, which was synthesized as described previously [20]. Urine samples were then subjected to solid phase extraction using Oasis HLB columns $(1 \mathrm{~mL}$, $30 \mathrm{mg}$, Waters Ltd., Elstree UK), evaporated to dryness and redissolved in $50 \mu \mathrm{L}$ of HPLC grade water The purified urine samples were subjected to liquid chromatography-electrospray ionization-tandem mass spectrometry (LC-ESI-MS/MS) with selected reaction monitoring (SRM) analysis by injecting a $10 \mu \mathrm{L}$ aliquot of each sample in triplicate as described previously [21]. Selected reaction monitoring analysis was performed for the $[\mathrm{M}+\mathrm{H}]^{+}$ion to oxidised base $\left[\mathrm{B}+\mathrm{H}_{2}\right]^{+}$transitions of 8 -oxodG, $m / z 284$ to 168 and the internal standard $\left[{ }^{15} \mathrm{~N}_{5}\right]$ 8-oxodG, $m / z 289$ to 173 . The level of 8-oxodG in each urine sample was determined from the ratio of the peak area of 8-oxodG to that of the internal standard and normalized to the specific gravity which was determined using a Reichert TS 400 refractometer (Reichert Analytical Instruments, Depew, USA). The levels of 8oxodG are expressed in $\mathrm{pmol} / \mathrm{mL}$ relative to a specific gravity of 1.036 which is the average of all the samples.

\section{Lung histology}

Whole lungs were fixed in formalin for 24 to $48 \mathrm{~h}$ and embedded in paraffin for histological sectioning. Sections were stained with hematoxylin and eosin and analysed under light microscopy (200 to $400 x$ ) by an experienced in veterinary pathologist blinded to exposure status.

\section{Statistical analysis}

Data are summarized as mean (standard error of the mean; SEM) and were analysed using GraphPad Prism 
version 5.03 (GraphPad Software Inc., La Jolla, CA). Survival results were validated by 4 separate experiments done at different times with $\mathrm{n}=10$ in each group. Comparison of survival was done by log rank test. Other data, except for the exploratory BAL cytokines data $(\mathrm{n}=$ 1 experiment), were validated by at least 3 separate experiments done at different time. Data were compared by the unpaired t test. A $P$ value of $<0.05$ was considered significant.

\section{Abbreviations}

AM: alveolar macrophage; BAL: bronchaoveloar lavage; CFU: colony forming unit; LC-ESI-MS/MS: liquid chromatography-electrospray ionization-tandem mass spectrometry; 8-oxoxdG: 8-oxo-deoxyGuanosine; PBS: phosphate buffered saline; PM: particulate matter; HPLC: high performance liquid chromatography; UF-CB: ultrafine carbon black

\section{Acknowledgements}

We thank Martyn Foster for performing the histological analysis of lung tissue. NIHR BRC in Microbial Disease provided infrastructural support for the human lavage study.

\section{Author details}

'Department of Infection Immunity and Inflammation, University of Leicester, Leicester, UK. ${ }^{2}$ Cancer Biomarkers and Prevention Group, Department of Cancer Studies, University of Leicester, LE1 7RH, UK. ${ }^{3}$ Liverpool School of Tropical Medicine, Liverpool L3 5QA, UK. ${ }^{4}$ Centre for Paediatrics, Blizard Institute of Cell and Molecular Science, Barts and the London School of Medicine and Dentistry, Queen Mary University London, London, E1 2AT, UK.

\section{Authors' contributions}

JG designed the experiments and wrote the manuscript. JG and PA supervised the experiments. PA critically revised the original version. AT and VF did the mouse experiments. AT helped design experiments, and contributed in drafting the manuscript. FT and RS performed the analysis of 8-oxoxdG. JR and SG performed the human lavage study and contributed to drafting the manuscript. All authors read and approved the final manuscript.

\section{Competing interests}

The authors declare that they have no competing interests.

Received: 5 August 2010 Accepted: 19 October 2010

Published: 19 October 2010

\section{References}

1. Wardlaw T, Salama P, Johansson EW, Mason E: Pneumonia: the leading killer of children. Lancet 2006, 368:1048-50.

2. Colbeck I, Nasir ZA, Ali Z: Characteristics of indoor/outdoor particulate pollution in urban and rural residential environment of Pakistan. Indoor Air 2010, 20:40-51.

3. Bruce N, Perez-Padilla R, Albalak R: Indoor air pollution in developing countries: a major environmental and public health challenge. Bull World Health Organ 2000, 78:1078-92.

4. Organisation WH: Analysis of estimates of the environmental attributable fraction, by disease. 2007, 33-56 [http://www.who.int/ quantifying_ehimpacts/publications/preventingdisease5.pdf], Accessed October 2010

5. Knapp S, Leemans JC, Florquin S, Branger J, Maris NA, Pater J, et al: Alveolar macrophages have a protective antiinflammatory role during murine pneumococcal pneumonia. Am J Respir Crit Care Med 2003, 167:171-9.

6. Lundborg M, Bouhafs R, Gerde P, Ewing P, Camner P, Dahlen SE, et al: Aggregates of ultrafine particles modulate lipid peroxidation and bacterial killing by alveolar macrophages. Environ Res 2007, 104:250-7.

7. Zhou H, Kobzik L: Effect of concentrated ambient particles on macrophage phagocytosis and killing of Streptococcus pneumoniae. Am J Respir Cell Mol Biol 2007, 36:460-5.
8. Kulkarni NS, Prudon B, Panditi SL, Abebe Y, Grigg J: Carbon loading of alveolar macrophages in adults and children exposed to biomass smoke particles. Sci Total Environ 2005, 345:23-30.

9. Fullerton DG, Jere K, Jambo K, Kulkarni NS, Zijlstra EE, Grigg J, et al: Domestic smoke exposure is associated with alveolar macrophage particulate load. Trop Med Int Health 2009, 14:349-54.

10. Kocbach A, Johansen BV, Schwarze PE, Namork E: Analytical electron microscopy of combustion particles: a comparison of vehicle exhaust and residential wood smoke. Sci Total Environ 2005, 346:231-43.

11. Yin XJ, Dong CC, Ma JY, Antonini JM, Roberts JR, Stanley CF, et al: Suppression of cell-mediated immune responses to listeria infection by repeated exposure to diesel exhaust particles in brown Norway rats. Toxicol Sci 2004, 77:263-71.

12. Zelikoff JT, Chen LC, Cohen MD, Schlesinger RB: The toxicology of inhaled woodsmoke. J Toxicol Environ Health B Crit Rev 2002, 5:269-82.

13. Sigaud S, Goldsmith CA, Zhou H, Yang Z, Fedulov A, Imrich A, et al: Air pollution particles diminish bacterial clearance in the primed lungs of mice. Toxicol Appl Pharmacol 2007, 223:1-9.

14. Jean D, Rezaiguia-Delclaux S, Delacourt C, Leclercq R, Lafuma C, BrunBuisson $C$, et al: Protective effect of endotoxin instillation on subsequent bacteria-induced acute lung injury in rats. Am J Respir Crit Care Med 1998, 158:1702-8.

15. Li XY, Brown D, Smith S, MacNee W, Donaldson K: Short-term inflammatory responses following intratracheal instillation of fine and ultrafine carbon black in rats. Inhal Toxicol 1999, 11:709-31.

16. Gallagher J, Sams R, Inmon J, Gelein R, Elder A, Oberdorster G, et al: Formation of 8-oxo-7,8-dihydro-2'-deoxyguanosine in rat lung DNA following subchronic inhalation of carbon black. Toxicol Appl Pharmacol 2003, 190:224-31.

17. Dick CA, Brown DM, Donaldson $\mathrm{K}$, Stone V: The role of free radicals in the toxic and inflammatory effects of four different ultrafine particle types. Inhal Toxicol 2003, 15:39-52.

18. Mudway IS, Duggan ST, Venkataraman C, Habib G, Kelly FJ, Grigg J: Combustion of dried animal dung as biofuel results in the generation of highly redox active fine particulates. Part Fibre Toxicol 2005, 2:6.

19. Kadioglu A, Gingles NA, Grattan K, Kerr A, Mitchell TJ, Andrew PW: Host cellular immune response to pneumococcal lung infection in mice. Infect Immun 2000, 68:492-501.

20. Singh R, McEwan M, Lamb JH, Santella RM, Farmer PB: An improved liquid chromatography/tandem mass spectrometry method for the determination of 8-oxo-7,8-dihydro-2'-deoxyguanosine in DNA samples using immunoaffinity column purification. Rapid Commun Mass Spectrom 2003, 17:126-34.

21. Teichert F, Verschoyle RD, Greaves P, Thorpe JF, Mellon JK, Steward WP, et al: Determination of 8-oxo-2'-deoxyguanosine and creatinine in murine and human urine by liquid chromatography/tandem mass spectrometry: application to chemoprevention studies. Rapid Commun Mass Spectrom 2009, 23:258-66.

doi:10.1186/1743-8977-7-30

Cite this article as: Tellabati et al: Acute exposure of mice to high-dose ultrafine carbon black decreases susceptibility to pneumococcal pneumonia. Particle and Fibre Toxicology 2010 7:30.

\section{Submit your next manuscript to BioMed Central and take full advantage of:}

- Convenient online submission

- Thorough peer review

- No space constraints or color figure charges

- Immediate publication on acceptance

- Inclusion in PubMed, CAS, Scopus and Google Scholar

- Research which is freely available for redistribution 